\title{
Altering the representation of hormones and adding consideration of gestational metabolism in a metabolic cow model reduced prediction errors
}

\author{
M. D. Hanigan, ${ }^{* 1}$ C. C. Palliser,$\dagger^{2}$ and P. Gregorini $\dagger$ \\ *Virginia Polytechnic Institute and State University, Blacksburg 24061 \\ †DairyNZ Ltd., Hamilton, New Zealand
}

\begin{abstract}
The model of R. L. Baldwin predicts various aspects of digestion and metabolism in the cow including nutrient partitioning between milk and body stores. However, prediction bias has been observed for body weight (BW) and body condition score (BCS) when diets of differing energy density are simulated over long periods. Originally, the model overpredicted BW loss in early lactation and gain in late lactation. This bias was reversed and limited to early lactation when a better representation of milk synthesis capacity was introduced into the model. It was hypothesized that a better representation of the effects of energy status on anabolic and catabolic hormones and a more complete representation of metabolic demands and growth associated with pregnancy would help in improving predictions of body tissue mobilization in early lactation. Providing independent glucose reference points and independent sensitivity scalars for the 3 hormones driven by glucose concentrations improved overall model precision. These improvements were primarily realized through reductions in prediction errors for blood glucose concentrations and BCS. In both cases, slope bias associated with the predictions was reduced, indicating that the changes in representation were beneficial although BCS bias was not completely removed. Milk component yields were predicted with slightly greater mean and slope bias. The addition of enhanced pregnancy calculations did not provide apparent additional benefit relative to model prediction errors. However, the data used for the assessments did not include observations from the last $60 \mathrm{~d}$ of gestation, where BW gain and metabolic demand associated with pregnancy would be expected to be greater. Improvements in BCS were not observed when the revised model was tested using an
\end{abstract}

\footnotetext{
Received November 23, 2008.

Accepted June 17, 2009.

${ }^{1}$ Corresponding author: mhanigan@vt.edu

${ }^{2}$ Current address: National Institute of Water \& Atmospheric Research Ltd, Gate 10, Silverdale Road, Hamilton 3216, New Zealand.
}

independent data set. Predictions of blood fatty acids, the rate of $\mathrm{BCS}$ and $\mathrm{BW}$ loss, and milk fat yields in early lactation were still inappropriate and require further work. The results could be caused by inaccurate early lactation intakes, the aggregated representation of blood fatty acids, or an inadequate representation of peripheral insulin resistance during early lactation.

Key words: model, lactation, milk composition, body weight

\section{INTRODUCTION}

The metabolic cow model of Baldwin et al. (1987a,b,c; referred to as Molly) predicts various aspects of digestion and metabolism in the cow including nutrient partitioning between milk and body stores. The model has been updated several times (Baldwin, 1995; Palliser et al., 2001; Beukes et al., 2004, 2005; Hanigan et al., 2006,2007 ) including alterations in the representation of milk synthesis enzymatic activity to address systematic bias in predicting milk yield and composition. These updates have improved prediction accuracy; however, challenges remain with predicting BW and body composition changes over the course of a lactation and in response to nutrient supply (Hanigan et al., 2007).

It was observed that the model generally overpredicted BW loss approaching peak lactation and BW gain in later lactation (McNamara and Baldwin, 2000). Additionally, predicted changes in milk yield were under-responsive to changes in dietary nutrients, which magnified the weight gain problem (Hanigan et al., 2008). As these simulations were run using the observed DMI and diet composition, the problem was not related to inappropriate DMI predictions. Attempts to address the issue by adjusting the basal energy expenditures were only partially successful (McNamara, 2004). However, systematic bias in predictions of milk yield and composition was a contributor to the BW problem. Redefining the representation of mammary cells and regulation of their activity to achieve improvements in predictions of milk yield and composition changed the nature of the problem, resulting in underprediction of 
BW and BCS loss and milk fat yield during the first 50 to $100 \mathrm{~d}$ of lactation (Hanigan et al., 2007). Because the model predicts partitioning of absorbed energy between maintenance, milk production, and body stores (for a full description of the scheme, see Baldwin, 1995), the observed prediction errors could result from inappropriate predictions of energy partitioning, although biased intake predictions cannot be ruled out.

Molly has been found to underpredict total-tract fiber and protein digestion and overpredict fat digestion when compared with a large set of literature data (Hanigan et al., 2006). However, digestion parameters were adjusted to remove the observed mean bias before the evaluations reported by Hanigan et al. (2007). It is possible that predictions of fiber digestion from herbage were still biased, because such observations were not present in the literature data set. Because digestibility evaluations were not conducted by Kolver et al. (2007), this hypothesis could not be tested. However, it seems unlikely that such bias would explain the observed bias as the problem would be present throughout lactation.

Because milk fat yield and blood fatty acid concentrations were both underpredicted in early lactation (Hanigan et al., 2007), it is possible that the early lactation problem results from inadequate responses to hormonal signals controlling body fat mobilization causing underprediction of blood fatty acids and milk fat output. Of course, this problem could result from very subtle errors in glucose concentrations that may drive greater errors in anabolic and catabolic hormones given the sensitivity of these hormones to blood glucose.

The original description of Molly did not include a representation of gestational gain or metabolic requirements to support that gain (Baldwin et al., 1987a,b). Energetic and AA demands to support gestation, but not gestational weight gain, were subsequently addressed (Baldwin, 1995). Although a representation of gestational gain would not appear to be linked to inadequate weight loss in early lactation, it would increase weight gain in late lactation that would allow an offsetting increase in the setting for basal energy requirements, which in turn would enhance weight loss in early lactation as demonstrated by McNamara (2004), thus helping to address the observed temporal bias.

It was hypothesized that the observed bias in predicting $\mathrm{BW}$ and $\mathrm{BCS}$ over the course of a lactation was due to 1) a combination of inadequate representation of the effects of glucose on hormonal concentrations and 2) an inadequate representation of gestational gain in late lactation. Thus, the objectives of this work were to 1 ) revise the representation of hormonal concentrations in Molly, 2) revise the representation of nutrient demands and BW gain associated with pregnancy in Molly, and 3) evaluate these revisions.

\section{MATERIALS AND METHODS}

The base model used for this work was that described by Baldwin (1995) with modifications as described by Hanigan et al. (2006, 2007). The digestive parameter settings listed in Table 1 were used for all simulations. These parameters were derived by fitting the model to the literature data set described by Hanigan et al. (2006) with no accommodation for experimental bias. Adoption of these digestion parameter settings reduced the root mean square prediction errors (RMSPE) for all ruminal and total-tract digestibility predictions by 10 percentage units or more, except for total-tract starch digestion, which had no change. Predictions of ruminal VFA and their molar percentages were also dramatically improved. Mean and slope bias were greatly reduced compared with values reported by Hanigan et al. (2006), which should ensure more accurate predictions of absorbed nutrients for the work described herein. The model with the above changes will be referred to as Molly2007. The revised model described herein will be referred to as Molly2008 (Molly2007 plus changes in hormonal and gestational representation).

Model coding changes were undertaken in ACSL (Ver. 11.8, Aegis Technologies Group, Austin, TX). Simulations and parameter estimations were conducted using ACSL Optimize (Ver. 2.5.4, Aegis Technologies Group) using a variable step, second-order Runge-Kutta-Fehlberg numerical integrator. The maximum integration interval was set to $0.01 \mathrm{~d}$. Parameters were estimated using a Nelder-Mead Simplex optimization algorithm to maximize a log-likelihood function. Residual errors were assumed to be homogeneous.

Revisions undertaken in Molly2008 are described below. A decision was made to start with the representation of hormonal control of tissue deposition and mobilization because the combination of errors in predicting fatty acids, milk fat, and body fat as well as sensitivity analyses offered strong evidence that this area of the model required attention.

\section{Tissue Responsiveness to Endocrines}

Two anabolic $\left(\boldsymbol{H}_{A n a b 1}\right.$ and $\left.\boldsymbol{H}_{\text {Anab2 } 2}\right)$ and one catabolic $\left(\boldsymbol{H}_{\text {Catab1 } 1}\right)$ hormones are represented as functions of the concentration of glucose in blood $\left(\boldsymbol{C}_{G l}, \mathrm{~mol} / \mathrm{L}\right)$ in Molly2007 with exponents to adjust sensitivity. A second catabolic hormone is defined in the model and was used in the 1995 version of the model as a positive effector of the conversion of AA to glucose. However, it was 
Table 1. Digestion parameter estimates derived by fitting the model to a data set from the literature (Hanigan et al., 2006) and model prediction accuracy

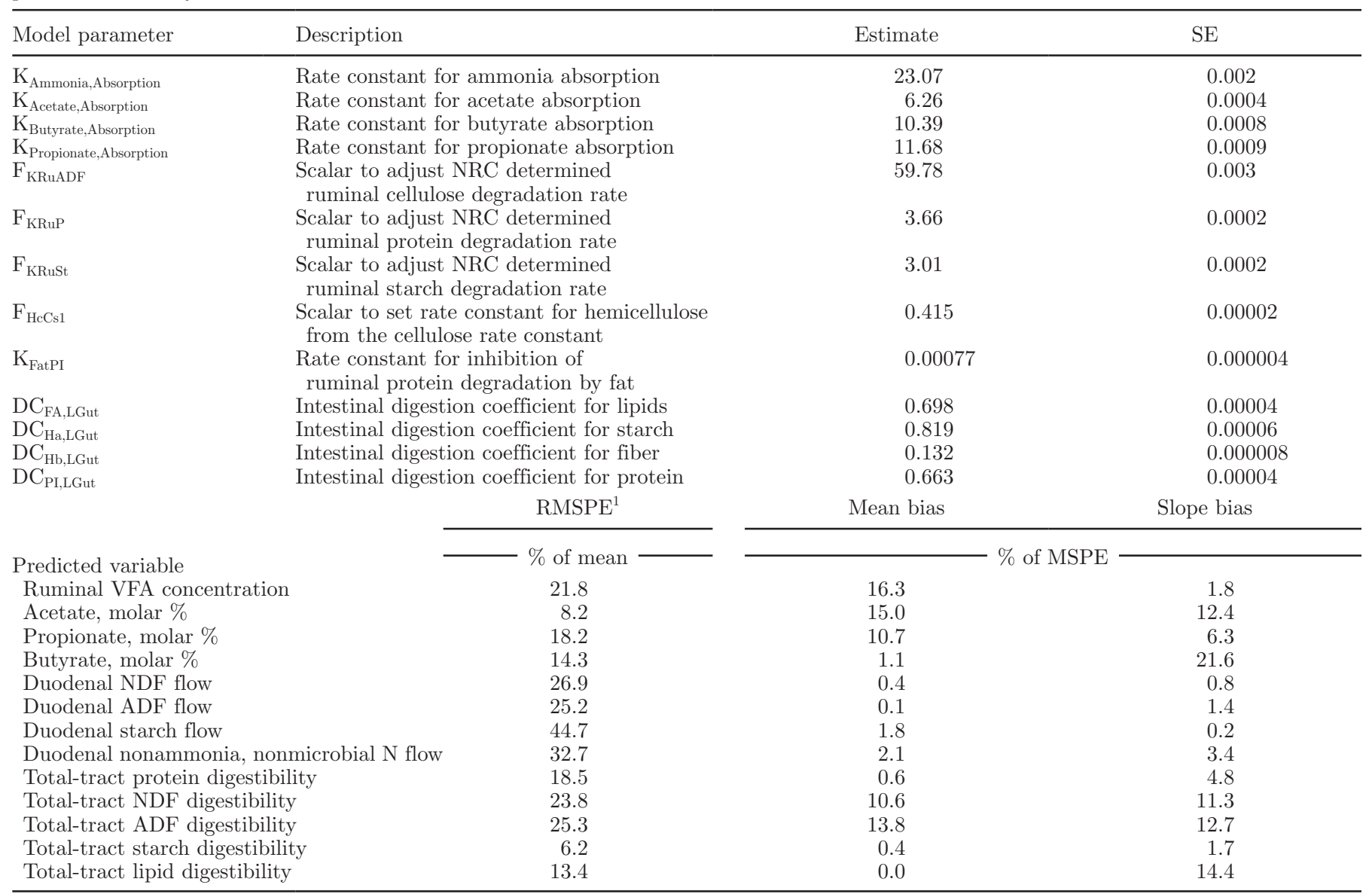

${ }^{1} \mathrm{RMSPE}=$ root mean square prediction error.

not used in earlier versions or in a later unpublished version of the model (AAMolly). This work and all of our previous work has been conducted with only one active catabolic hormone; that is, no hormonal effect on AA conversion to glucose. The 2 anabolic hormones were originally represented using the ratio of $C_{G l}$ to the initial $C_{G l}\left(i C_{G l}\right)$ to generate predicted hormonal concentrations. The general form of the anabolic equation was

$$
H_{\text {Anab }}=\left(C_{G l} / i C_{G l}\right)^{\text {Theta }},
$$

where Theta was used to adjust sensitivity to $C_{G l}$. The catabolic equation used an inverted glucose ratio $\left(i C_{G l}\right)$ $\left.C_{G l}\right)$. Theta was the same for $H_{\text {Anab1 } 1}$ and $H_{\text {Catab1 } 1}$, but $H_{\text {Anab2 }}$ used a greater value for Theta; thus, the magnitude of the changes associated with changing $C_{G l}$ were greater.
Although not explicitly defined, the aggregated representations $H_{\text {Anab1 } 1}$ and $H_{\text {Anab2 }}$ primarily represent insulin effects, and $H_{\text {Catab1 } 1}$ represents the actions of glucagon and catecholamine. These hormones affect body fat synthesis $(\mathrm{mol} / \mathrm{d})$ from long-chain fatty acids $\left(H_{\text {Anab1 } 1}\right)$ and acetate $\left(H_{\text {Anab } 1}\right.$ and $\left.H_{\text {Anab } 2}\right)$, lipolysis in adipose $\left(H_{\text {Catab1 } 1}\right)$, protein synthesis in the body and viscera $\left(H_{\text {Anab1 }}\right)$, and the rate of glucose oxidation $\left(H_{\text {Anab1 }}\right)$. Thus, having a robust representation of their concentrations is critical to nutrient partitioning and body composition.

Because the reference concentration of glucose was fixed at a common value for both anabolic and catabolic hormones, processes affected by those hormones were centered at a common $i C_{G l}$, which may not reflect reality. Also, by using a common sensitivity exponent for $H_{\text {Anab2 } 2}$ and $H_{\text {Catab1 } 1}$, the ability to adjust those functions independently was negated. To test whether hormonal regulation would benefit from the use of different reference points for glucose and differing sensitivity exponents, the original representations were modified. 
Reference parameters for glucose effects on each hormone were changed to independent constants to delink the reference state from initial concentrations of glucose, and independent Theta values were introduced for each equation:

$$
\begin{aligned}
& H_{\text {Anab1 } 1}=\left(C_{G l} / R_{\text {Anab1 }}\right)^{\text {Theta } 1}, \\
& H_{\text {Anab2 }}=\left(C_{G l} / R_{\text {Anab2 }}\right)^{\text {Theta } 2}, \\
& H_{\text {Catab1 }}=\left(R_{\text {Catab1 }} / C_{G l}\right)^{\text {Theta } 3} .
\end{aligned}
$$

These changes allowed the reference constants $\left(R_{x x x}\right.$, $\mathrm{mol} / \mathrm{L}$ ) and sensitivity coefficients to be derived independently for each hormone class, which would alter their effects on BW and BCS gain and loss throughout lactation.

\section{Gestational Growth and Metabolic Demand}

Molly2007 was modified to include consideration of body mass increases and use of metabolites associated with pregnancy. The model of Koong et al. (1975) was used to represent conceptus and uterine growth after fitting to the observations of Bell et al. (1995). The latter ensured that gravid uterine growth patterns were characteristic of Holsteins. The model was modified to provide for uterine involution postpartum, which was required to avoid discontinuities in uterine and body mass at calving:

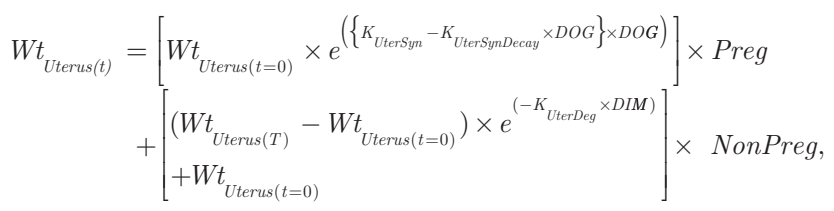

where $W t_{\text {Uterus }(t)}$ represented the uterine mass $(\mathrm{kg}$ of fresh weight) at any time $t, W t_{\text {Uterus }(t=0)}$ represented the nonpregnant, fully involuted uterine mass ( $\mathrm{kg}$ of fresh weight), and $W t_{\text {Uterus }(T)}$ represented the uterine mass at parturition $(t=283 \mathrm{~d} ; \mathrm{kg}$ of fresh weight); $K_{\text {UterSyn }}$ and $K_{\text {UterSynDecay }}$ represented rate constants for synthesis of uterine tissue $\left(\mathrm{d}^{-1}\right)$ and the rate of decay of that synthesis rate as parturition approaches $\left[\left(\mathrm{d}^{-1}\right)^{2}\right]$, respectively; $K_{\text {UterDeg }}$ represented the rate constant for uterine degradation $\left(\mathrm{d}^{-1}\right)$. The difference between uterine synthesis and degradation yields a net growth rate. Preg and NonPreg were integers set to values of 1 and 0 when day of gestation $(D O G$; equation [10]) was $\geq 0$ and 0 and 1 , respectively, when $D O G$ was $<0$. Uterine mass at parturition $\left(W t_{\text {Uterus }(T)}\right)$ was calculated as

$W t_{\text {Uterus }(T)}=W t_{\text {Uterus }(t=0)} \times e^{\left[\left(K_{\text {UterSyn }}-K_{\text {UterSynDecay }} \times \text { GestLength }\right) \times \text { GestLength }\right]}$,

where GestLength represented gestation length (d). Conceptus mass at any time $t\left(W t_{\text {Conceptus }(t)}\right)$ was calculated as

$W t_{\text {Conceptus }(t)}=W t_{\text {Conceptus }(t=0)} \times e^{\left.\left(\left[K_{\text {Conesyn }}-K_{\text {ConeSynDecay }} \times D O G\right] \times D O G\right)\right)}$,

where $W t_{\text {Conceptus }(t=0)}$ represented the weight of the conceptus at conception $(\mathrm{kg})$ and $K_{\text {ConcSyn }}$ and $K_{\text {ConcSynDecay }}$ represented rate constants for synthesis of conceptus tissue $\left(\mathrm{d}^{-1}\right)$ and the rate of decay of that synthesis rate as parturition approaches $\left[\left(\mathrm{d}^{-1}\right)^{2}\right]$, respectively. Gravid uterine mass was represented as the sum of uterine and conceptus mass:

$$
W t_{\operatorname{GrvUter}(t)}=W t_{\operatorname{Conceptus}(t)}+W t_{\operatorname{Uterus}(t)} .
$$

Days in milk $(D I M)$ and $D O G$ were calculated from time $(t)$ using MOD functions, which return the remainder when argument 1 is divided by argument 2 . They were applied in the following manner:

$$
\begin{aligned}
D I M & =M O D(t+\text { DaysDry }+i D I M, \text { CalvingInterval }) \\
& - \text { DaysDry } \\
\text { DOG }= & \text { MOD }(t+i \text { DOG }+ \text { DaysOpen, CalvingInterval }) \\
& - \text { DaysOpen },
\end{aligned}
$$

where $i D I M$ (initial DIM), $i D O G$ (initial DOG), DaysDry (days dry), DaysOpen (days open), all with units of days, were required inputs. Calving interval (CalvingInterval, d) was calculated from DaysOpen and GestLength as:

$$
\text { CalvingInterval }=\text { GestLength }+ \text { DaysOpen } .
$$

These functions allow multiple lactations to be simulated without resetting the model. 
Because the conceptus includes uterine fluid, which is not a constant proportion of conceptus mass over time, a separate equation was used to predict conceptus protein mass $\left(W t P_{\text {Conceptus }} ; \mathrm{kg}\right)$ at any time $t$ :

$$
\begin{aligned}
W t P_{\text {Conceptus }(t)} & =W t P_{\text {Conceptus }(t=0)} \\
& \times e^{\left(\left[K_{P \text { ConcSyn }}-K_{P C o n c S y n D e c a y} \times D O G\right] \times D O G\right)},
\end{aligned}
$$

where $W t P_{\text {Conceptus }(t=0)}$ represented the weight of protein in the conceptus at conception $(\mathrm{kg})$ and $K_{P C o n c S y n}$ and $K_{P C o n c \text { SynDecay }}$ represented rate constants for synthesis of conceptus protein $\left(\mathrm{d}^{-1}\right)$ and the rate of decay of that synthesis rate as parturition approaches $\left[\left(\mathrm{d}^{-1}\right)^{2}\right]$, respectively. Equations [5] to [7] and [12] were represented in analytical form because of the availability of such solutions and the need for precise predictions of uterine and conceptus mass at any point in time. It was determined that the use of numerical integration resulted in very poor precision when simulating conceptus growth given an initial conceptus mass near zero and the comparatively large step sizes taken by the variable step integrator to achieve reasonable solution times.

Baldwin et al. (1987a) utilized initial empty BW $(i E B W)$ to scale pool sizes and rate constants for several metabolic processes including rates of protein and fat synthesis in the body. Although such an approach provides for scaling of the model across large ranges in body size, changes in gravid uterine mass associated with gestational age would result in variable initial rate constants and pool sizes for the carcass and viscera of a given animal depending on the DOG at the start of the simulation. Because carcass and visceral growth are better represented as functions of the current quantity of DNA relative to the quantity of DNA at maturity and the ratio of protein to DNA (di Marco et al., 1987), gravid uterine mass should not affect those rates. To prevent such a problem, initial body mass was partitioned in the following manner:

$$
\begin{gathered}
i E B W_{\text {NonFat }}=i E B W_{\text {Total }}-i W t_{\text {Adip }}, \\
i E B W_{\text {NonFatNonUter }}=i E B W_{\text {NonFat }}-W t_{\text {GrvUter }(t=0)}, \\
i E B W_{\text {NonUter }}=i E B W_{\text {Total }}-W t_{\text {GrvUter }(t=0)}, \\
i W t_{\text {Oth }}=i E B W_{\text {NonFatNonUter }} \times 0.82, \\
i W t_{\text {Vis }}=i E B W_{\text {NonFatNonUter }}-i W t_{\text {Oth }},
\end{gathered}
$$

where $i W t_{\text {Adip }}$, $i W t_{\text {Oth }}$, and $i W t_{\text {Vis }}$ represented the initial weights $(\mathrm{kg})$ of adipose, carcass, and visceral compartments at the initiation of a simulation as originally described by Baldwin et al. (1987a); body weight factor $(B W F, \mathrm{~kg})$ thus represented $E B W$ minus the weight of the gravid uterus, and this factor was used to scale initial pool sizes and rate constants as originally represented in Molly; $i W t_{\text {Adip }}$ was predicted based on the equations of Waltner et al. (1994) as described by Hanigan et al. (2006). Similar equations were used to track compartmental mass through time:

$$
\begin{gathered}
\frac{\mathrm{d} E B W_{\text {Total }}}{\mathrm{d} t}=\frac{\mathrm{d} W t_{\text {Oth }}}{\mathrm{d} t}+\frac{\mathrm{d} W t_{\text {Adip }}}{\mathrm{d} t}+\frac{\mathrm{d} W t_{\text {Vis }}}{\mathrm{d} t}+\frac{\mathrm{d} W t_{\text {GrvUter }},}{\mathrm{d} t} \\
E B W_{\text {Total }}=W t_{\text {Oth }}+W t_{\text {Adip }}+W t_{\text {Vis }}+W t_{\text {GrvUter }}, \\
E B W_{\text {NonFat }}=E B W_{\text {Total }}-W t_{\text {Adip },} \\
E B W_{\text {NonFatNonUter }}=E B W_{\text {NonFat }}-W t_{\text {GrvUter }}, \\
E B W_{\text {NonUter }}=E B W_{\text {Total }}-W t_{\text {GrvUter }},
\end{gathered}
$$

where $\mathrm{d} E B W_{\text {Total }} / \mathrm{d} t$ represented the differential equation describing $E B W$ change over time.

Additional changes in the representation of AA and energy metabolism were required to represent AA and energy use by the gravid uterus. These changes were essentially all stoichiometric equations and are detailed in the appendix.

\section{Parameter Estimation and Model Evaluations}

Equations [5] to [12] were developed initially as an independent model and fitted to the data of Bell et al. (1995) by maximizing the log-likelihood function (LLF) using ACSL Optimize. As the data were inadequate to define the initial weights of the uterus, conceptus, and conceptus protein, the initial fresh weights of Ferrell et al. (1976a) were adopted (204, 470, and $0.77 \mathrm{~g}$, respectively). Data were also not available to define the regression of uterine mass after parturition $\left(k_{\text {UterDeg }}\right)$ and thus it was set to a value of 0.2 , which resulted in a $91 \%$ reduction in uterine mass in the first $2 \mathrm{wk}$ after parturition and essentially full involution $(97 \%)$ by 4 wk (Harrison et al., 1986). After parameterization of gravid uterine growth, equations [5] to [12] were incorporated into Molly as described above. The parameters governing growth of the gravid uterus were assumed 
independent of hormonal effects, and thus were fixed during parameter estimation work with Molly2008.

One data set was used for initial model evaluations of Molly2007 and subsequent parameter estimations, and a second independent data set was used for evaluations of Molly2008 after parameter estimations were completed. The first data set consisted of observations that were collected as part of an extended lactation trial conducted in New Zealand (Kolver et al., 2007). Multiparous Holstein-Friesian cows of North American or New Zealand genotype were fed 0,3 , or $6 \mathrm{~kg}$ of concentrate DM daily while grazing pasture ad libitum throughout a $>600 \mathrm{~d}$ lactation. Breeding was initiated at 450 DIM. The $42-\mathrm{d}$ pregnancy rate was 79 and $56 \%$, respectively, for the New Zealand and North American genotypes, with final nonpregnancy rates of 3 and $30 \%$, respectively. Intake was calculated using the equation of Holmes et al. (2002) and used as a model input along with the diet composition as determined from monthly observations of grass analyses and tabular values for the grain mix. Observed values included milk yield and composition, BW, BCS, and plasma urea, glucose, and NEFA. Molly does not have separate pools for NEFA and blood triacylglycerides (TAG), which poses a problem in terms of fitting to the observed data. We previously chose to rescale the pool to reflect the observed NEFA pool size so that predicted and observed NEFA concentrations could be compared. All inputs and outputs remained the same, so this change would not affect the overall operation of the model and is analogous to the pool size scaling undertaken in other parts of the model to reduce solution time and provide model stability (Baldwin, 1995), albeit in the reverse direction. An alternative approach would have been to scale the observed data to reflect some assumed concentration of TAG. Both methods lead to the same result.

The second data set consisted of the observed treatment means from the experiment of Aston et al. (1995). Observed data included DMI, diet composition, milk yield, milk composition, and BW. The observed intakes and diet composition were used as model inputs (Hanigan et al., 2007, 2008). Molly2007 was fitted to milk yield, milk component yields, milk component percentages, $\mathrm{BW}$, and $\mathrm{BCS}$ to determine the appropriate genetic settings for the number of mammary cells (QCells $(t=0)$, sets the capacity for all milk components), the maximal capacity for lactose production $\left(V m_{G l, L m(t=0)}\right.$, scales milk lactose production, which changes milk fat and protein content), and the maximal capacity for milk protein production ( $V m_{A a, P m}$, scales milk protein content). Molly2007 was refitted to the data because one additional observed variable, milk lactose percentage, was used compared with the previous fit. Molly2008 was tested against the same data set using the parameters derived from fitting the model to the extended lactation data set and the above 3 genetic scalars; that is, it was not refitted to the data.

Parameter estimates related to hormones were derived with and without the pregnancy model to test the effects of alterations in the representation of hormones and the benefits of a better representation of pregnancy. Hormonal parameters that were derived were $R_{\text {Anab1 } 1}, R_{\text {Catab1 } 1}$, Theta1, and Theta3. As no observations of acetate concentrations in blood were available, no attempt was made to derive values for $R_{\text {Anab2 }}$ and default values for that hormone were retained; that is, $R_{\text {Anab2 }}$ was set equal to $i C_{G l}$ and the previously defined value for Theta2 was retained. All parameters were derived simultaneously while fitting against milk yield, milk component yields, milk component percentages, blood NEFA, blood glucose, blood urea, BW, and BCS. All fitting variables were weighted equally.

Because the above changes would affect blood metabolite concentrations and partitioning of metabolites, parameters defining the number of active mammary cells and activity per cell, basal metabolic rate, and storage of fatty acids in adipose were also re-derived as described previously (Hanigan et al., 2007).

Residual prediction errors were calculated as observed minus predicted values, and RMSPE and a decomposition of those errors were calculated from the residuals as described previously (Roseler et al., 1997). Slope bias was determined by regression of residuals on the predicted values.

\section{RESULTS AND DISCUSSION}

\section{Hormonal Changes}

The data were adequate to describe the added hormonal parameters as evidenced by standard deviations for parameter estimates that were $<20 \%$ of the estimates in all cases (Table 2). Correlation among parameters was $<0.1$ for all parameters except for the parameters describing synthesis $\left(k_{V m, S y n}\right)$ and decay $\left(k_{V m, \text { Decay }}\right)$ of the enzymatic activity for conversion of glucose to lactose in the mammary glands $(\mathrm{R}=0.98)$ and Theta3 and $\phi$ $(\mathrm{R}=0.91)$, the latter being a sensitivity exponent for the effect of lactation hormone on mammary cell activity (a proxy for the somatotropin axis; see Hanigan et al., 2007, for a full description of these parameters). In neither case did correlations among parameters appear to contribute to significant variance inflation in the parameter estimates.

Separation of the definition of initial glucose concentrations and reference points for $H_{\text {Anab1 } 1}$ and $H_{C a t a b 1}$ and fitting to the observed data resulted in reference points of $0.0032 \pm 1.2 \times 10^{-6}$ and $0.00328 \pm 1.2 \times 10^{-6} \mathrm{M}$, 
Table 2. Parameter estimates derived from fitting the revised model to the extended lactation data set ${ }^{1}$

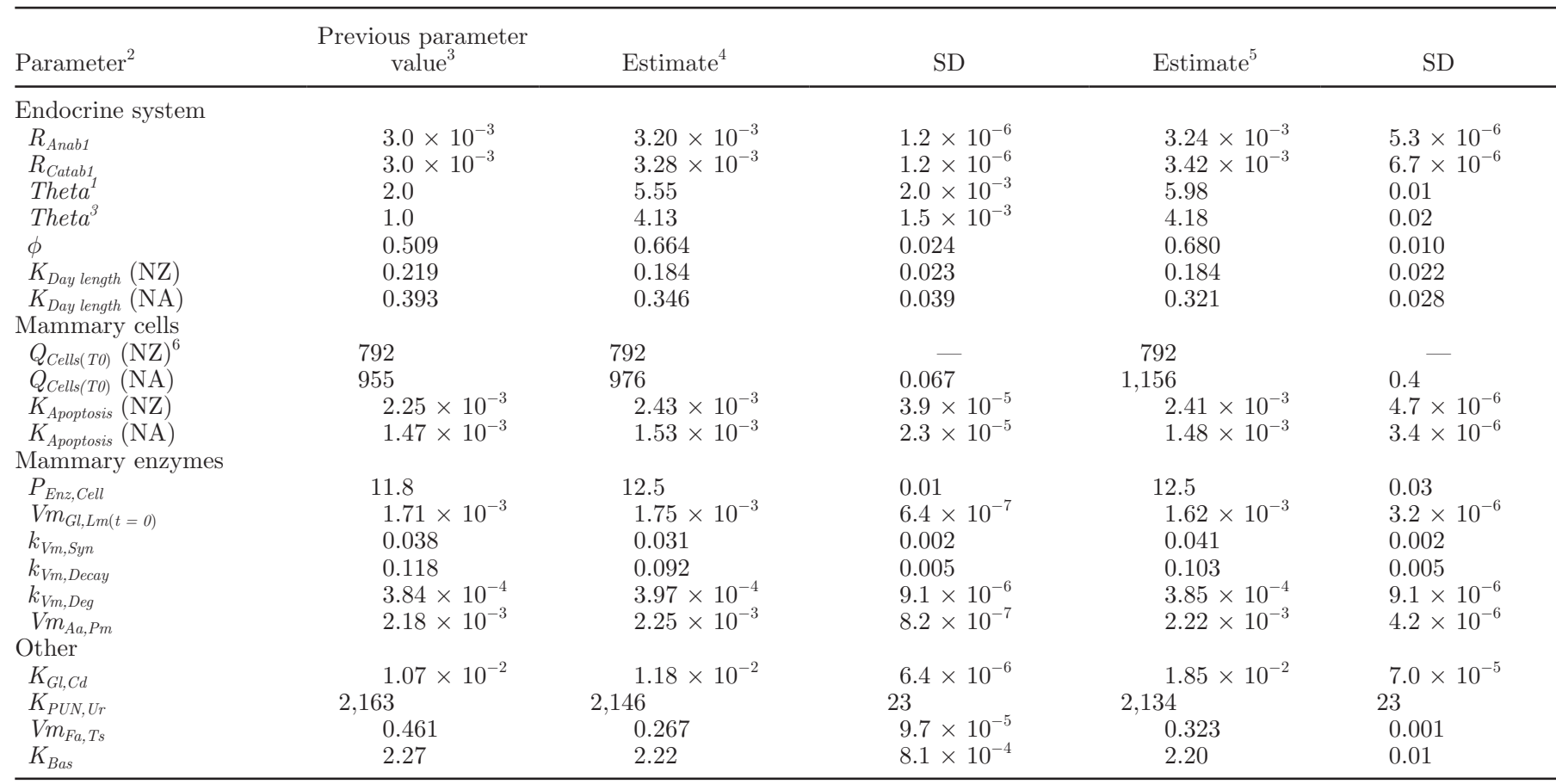

${ }^{1} Q_{\text {Cells }(T O)}, K_{\text {Apoptosis }}$, and $K_{\text {Day length }}$ were fit by genotype where genotypes were North American (NA) and New Zealand (NZ) Holstein-Friesians.

${ }^{2} R_{\text {Anab1 } 1}, R_{\text {Catab } 1}$, Theta ${ }^{1}$, and Theta ${ }^{3}$ are defined in equations [2] and [4]. The remaining parameters are described by Hanigan et al. (2007).

${ }^{3}$ From Hanigan et al. (2007).

${ }^{4}$ Molly2008 with only the revised representations of $H_{\text {Anab } 1}, H_{\text {Anab } 2}$, and $H_{\text {Catab1 }}$.

${ }^{5}$ Molly2008 with revised representations of $H_{\text {Anab1 } 1}, H_{\text {Anab } 2}, H_{\text {Catab } 1}$, and pregnancy calculations.

${ }^{6}$ Fixed at 792 to maintain a common reference point with previous versions of the model. See Hanigan et al. (2007) for a description.

respectively. The increases in the reference glucose concentration from the original $0.003 M$ increases the point at which anabolic and catabolic hormonal signals are equal, which would favor greater fat mobilization under nutritional stress, particularly in early lactation, and dampen fat deposition during times of energy surplus. More striking were the derived sensitivity exponents of $5.55 \pm 0.002$ and $4.13 \pm 0.002$ for $H_{\text {Anab } 1}$ and $H_{\text {Catab } 1}$, respectively, compared with the historic values of 2 and 1 assumed by Baldwin (1995). These greater exponents would dramatically increase the hormonal concentration responses to deviations in glucose concentrations from the reference points and thus enhance anabolic and catabolic responses to changing glucose concentrations.

The revised parameter estimates for $H_{\text {Anab1 }}$ and $H_{\text {Catab1 } 1}$ resulted in a greater estimate of the sensitivity exponent $\phi$ and lesser values for the effect of day length on lactation hormone synthesis $\left(k_{\text {Day length }}\right)$. Estimates of rates of cell death $\left(k_{\text {Apoptosis }}\right)$ were greater than previously derived for animals of the New Zealand genotype but not dramatically different for animals of the North American genotype, and the capacity for deposition of fat in adipose $\left(V m_{F a, T s}\right)$ was halved relative to prior estimates (Hanigan et al., 2007). These changes in parameter estimates are consistent with the transfer of greater control of anabolic and catabolic states to endocrine signals, thus enhancing the propensity to synthesize milk and deposit fat in adipose stores in late lactation under anabolic conditions, which must be offset by a greater loss of mammary cells and a reduction in the intrinsic capacity for fat deposition if milk yield and $\mathrm{BW}$ gain are to be predicted without bias.

The prediction errors for Molly2007 and Molly2008 are presented in Table 3 . The overall effects of changes in $H_{\text {Anab } 1}$ and $H_{\text {Catab1 } 1}$ on prediction errors for the extended lactation data set were not dramatic, with an increase in the LLF of slightly greater than $6 \%$. The largest improvements in prediction accuracy were for blood glucose concentrations and BCS where RMSPE were reduced by $25 \%$ or more. The proportion of prediction errors associated with slope bias was reduced dramatically for both and mean bias was reduced for BCS. Although an overall reduction in prediction error was realized, the reductions in glucose and BCS prediction errors were associated with slightly greater prediction errors for milk and milk component yields and an increase in the proportion of prediction errors associated with slope bias for milk protein and fat yields. Prediction errors for BW were improved 
Table 3. Root mean square prediction errors (RMSPE) for the Molly model $^{1}$

\begin{tabular}{|c|c|c|c|c|c|}
\hline Variable & Molly $2007^{2}$ & $\begin{array}{l}\text { Molly } 2008^{3} \\
\text { (hormones) }\end{array}$ & $\begin{array}{l}\text { Molly } 2008^{4} \\
\text { (pregnancy) }\end{array}$ & Molly $2007^{5}$ & Molly $2008^{6}$ \\
\hline & \multicolumn{3}{|c|}{ Extended lactation data } & \multicolumn{2}{|c|}{ — Aston et al. (1995) data - } \\
\hline Log-likelihood & 4,245 & 4,525 & 4,573 & -149 & -173 \\
\hline Added parameters & - & 4 & 10 & - & 10 \\
\hline \multicolumn{6}{|l|}{ RMSPE, $\%$ of observed mean } \\
\hline Milk yield & 7.7 & 8.1 & 7.9 & 3.9 & 4.8 \\
\hline Lactose yield & 8.3 & 8.7 & 8.5 & 3.7 & 3.8 \\
\hline Protein yield & 9.4 & 10.0 & 9.9 & 4.8 & 4.6 \\
\hline Fat yield & 11.6 & 12.2 & 12.1 & 7.2 & 7.3 \\
\hline Lactose, \% & 5.1 & 5.1 & 5.1 & 0.9 & 0.9 \\
\hline Protein, $\%$ & 5.4 & 5.4 & 5.5 & 3.5 & 3.5 \\
\hline Fat, $\%$ & 9.2 & 9.0 & 9.2 & 7.0 & 6.3 \\
\hline Blood glucose concentration & 12.4 & 7.9 & 7.7 & & \\
\hline Blood NEFA concentration & 87.4 & 85.1 & 85.6 & & \\
\hline Blood urea concentration & 20.8 & 20.5 & 20.5 & & \\
\hline BW & 5.7 & 5.6 & 5.4 & 3.4 & 3.6 \\
\hline BCS & 21.7 & 15.2 & 15.1 & 14.7 & 15.1 \\
\hline \multicolumn{6}{|l|}{ Mean bias, $\%$ of MSPE } \\
\hline Milk yield & 0.03 & 0.001 & 0.01 & 0.2 & 0.002 \\
\hline Lactose yield & 0.0004 & 0.01 & 0.01 & 3.1 & 5.6 \\
\hline Protein yield & 0.2 & 0.3 & 0.3 & 0.2 & 2.8 \\
\hline Fat yield & 0.01 & 0.3 & 0.3 & 9.5 & 29.2 \\
\hline Lactose, \% & 16.0 & 16.0 & 16.0 & 0.5 & 0.5 \\
\hline Protein, \% & 0.2 & 0.2 & 0.2 & 0.0005 & 2.9 \\
\hline Fat, $\%$ & 0.3 & 0.1 & 0.01 & 12.4 & 13.2 \\
\hline Blood glucose concentration & 0.3 & 0.1 & 0.1 & & \\
\hline Blood NEFA concentration & 0.1 & 2.0 & 1.2 & & \\
\hline Blood urea concentration & 1.8 & 1.7 & 1.7 & & \\
\hline BW & 0.1 & 2.5 & 2.2 & 21.4 & 0.5 \\
\hline $\mathrm{BCS}$ & 39.0 & 5.4 & 5.0 & 51.4 & 44.5 \\
\hline \multicolumn{6}{|l|}{ Slope bias, $\%$ of MSPE } \\
\hline Milk yield & 1.5 & 4.5 & 5.3 & 4.7 & 0.4 \\
\hline Lactose yield & 3.1 & 0.6 & 0.4 & 21.3 & 0.8 \\
\hline Protein yield & 9.9 & 15.2 & 17.6 & 72.5 & 30.6 \\
\hline Fat yield & 7.6 & 14.3 & 15.0 & 66.7 & 32.8 \\
\hline Lactose, \% & 0.001 & 0.00001 & 0.00001 & 0 & 0 \\
\hline Protein, \% & 1.0 & 0.3 & 0.7 & 0.003 & 0.004 \\
\hline Fat, $\%$ & 10.0 & 9.0 & 10.5 & 58.7 & 51.3 \\
\hline Blood glucose concentration & 65.7 & 17.1 & 14.2 & & \\
\hline Blood NEFA concentration & 6.1 & 3.2 & 2.8 & & \\
\hline Blood urea concentration & 43.2 & 42.1 & 42.3 & & \\
\hline BW & 3.9 & 11.1 & 9.6 & 50.5 & 68.4 \\
\hline $\mathrm{BCS}$ & 17.3 & 5.5 & 3.8 & 48.0 & 54.9 \\
\hline
\end{tabular}

${ }^{1}$ Root mean square prediction errors are expressed as a percentage of the observed mean. Mean and slope bias are expressed as a percentage of the mean square prediction error (MSPE).

${ }^{2}$ Model parameters were derived, whereas stoichiometries for VFA production were assumed constant regardless of grain supplementation.

${ }^{3}$ Molly2008 with a revised representation of $H_{\text {Anab } 1}, H_{\text {Anab } 2}$, and $H_{\text {Catab1 } 1}$ after fitting to the extended lactation data set. Derived parameters are listed in Table 2.

${ }^{4}$ Molly2008 with a revised representation of $H_{\text {Anab } 1}, H_{\text {Anab } 2}$, and $H_{\text {Catab1 }}$, and pregnancy calculations after fitting to the extended lactation data set. Parameter estimates are provided in Table 2.

${ }^{5}$ Predictions were from Molly2007 with the following setting modifications: $Q_{C e l l s(T 0)}=766, V m_{G l . L m(t=0)}=1.70$ $\times 10^{-3}$, and $V m_{A a, P m}=1.97 \times 10^{-3}$ to accommodate genetic differences in milk yield and composition.

${ }^{6}$ As for footnote 4 but with $Q_{\text {Cells }(t=0)}=649, V m_{G l, L m(t=0)}=1.70 \times 10^{-3}$, and $V m_{A a, P m}=2.12 \times 10^{-3}$.

slightly in overall error but there was a slight increase in the proportion of slope bias. Therefore, the overall improvement in blood glucose, BCS, and BW came at a slight cost in prediction accuracy for milk yield and composition.

Predictions of milk fat were not improved and blood fatty acid predictions were only slightly improved by the changes in $H_{\text {Anab1 } 1}$ and $H_{\text {Catab1 } 1}$. Prediction bias for
BW mobilization and blood fatty acid concentrations in early lactation remained virtually unchanged from previous observations [Figure 1 and Hanigan et al. (2007)] with both being underpredicted, which might be because of inaccurate predictions of DMI. If intake were overpredicted during this period, energy supply to the animal would be less than that predicted. Reducing feed input to the model would then result in decreased 

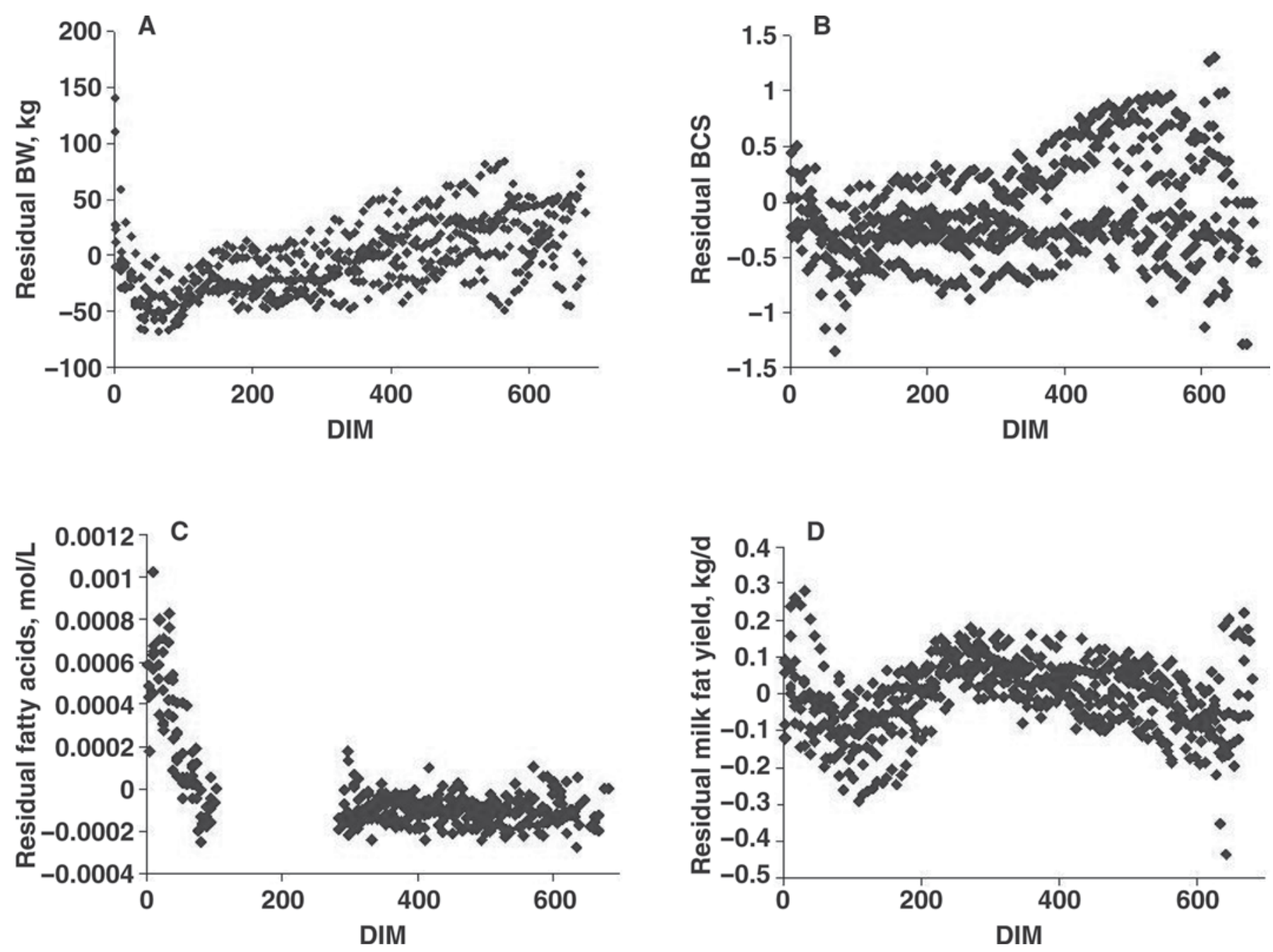

Figure 1. Residual errors for predictions of BW (A), BCS (B), blood fatty acids (C), and milk fat yields (D) for an extended lactation trial using Molly2008 including changes in hormonal representation and the gestational submodel. Parameter estimates listed in Table 4 were used for the simulations.

blood glucose concentrations leading to increased fat mobilization and BW loss. However, because blood glucose concentrations were predicted with good precision and very little bias, any reduction in glucose precursor supply would lead to a bias in blood glucose predictions.

If intake is predicted appropriately, the results support the occurrence of peripheral insulin resistance in the early lactation period resulting in reduced lipogenesis and re-esterification in adipose and thus reduced removal of fatty acids from blood (McNamara et al., 1995). The increased blood fatty acid concentrations would then lead to increased milk fat yield, which is consistent with the observed bias.

An alternative hypothesis is that milk fat errors are due to the aggregated treatment of blood fatty acids in Molly. Rate parameters for removal of NEFA and TAG by mammary tissue have been observed to be 4 -fold different (Hanigan et al., 1998). This diversity in mammary affinity for TAG versus NEFA could lead to poor predictions of fatty acid supply to the mammary when the pools are considered in aggregate if blood NEFA and TAG concentrations move independently, which is certainly the case in early lactation (Smith et al., 1978; Vazquez-Anon et al., 1994). Because milk fat synthesis is clearly related to blood NEFA concentrations and presumably also to blood TAG concentrations (Pullen et al., 1989), errors in predicting fatty acid supply to the mammary tissue would result in poor predictions of milk fat. Thus, an accurate representation of mammary affinity for NEFA and TAG may lead to more accurate predictions of changes in milk fat.

\section{Pregnancy}

Parameter estimates derived from fitting the gravid uterine growth model to the data of Bell et al. (1995) 


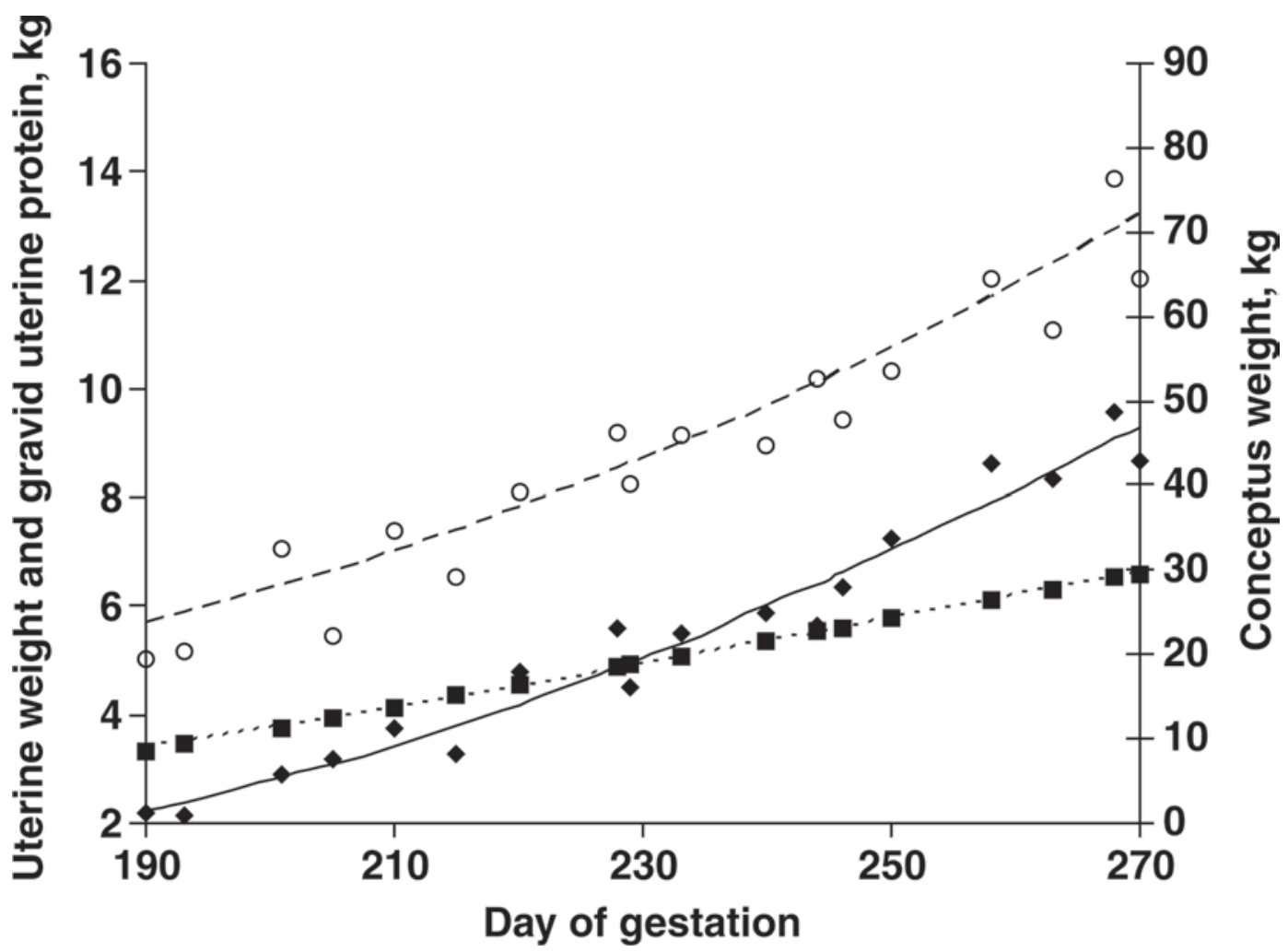

Figure 2. Predicted (lines) and observed (points) gravid uterine protein $(-,-)$, conceptus tissue $(---, O)$, and uterine tissue $(----, \mathbf{\square})$ weights of Holstein-Friesian cows. Predictions are from equations [5] to [12] fitted to the observed values of Bell et al. (1995). Observed protein values were derived from observed DM values using the regression equation of Bell et al. (1995).

are presented in Table 4. All estimates were uniquely defined and well resolved as evidenced by standard errors less than $15 \%$ of the parameter estimates. Predicted and observed uterine and conceptus weights are plotted in Figure 2 for an average animal, and predictions of weights through an entire pregnancy cycle are presented in Figure 3.

The initial synthesis rate of conceptus fresh weight was $2.54 \% / \mathrm{d}$, which is slightly greater than the $2.17 \% / \mathrm{d}$ observed by Ferrell et al. (1976a) for beef cattle. The rate of decline in the instantaneous conceptus growth rate as parturition approaches also was greater for Holsteins $\left(0.0025 \% / \mathrm{d}^{2}\right)$ than for beef cattle $(0.0016 \% /$ $\left.\mathrm{d}^{2}\right)$. The increased synthesis rate is consistent with the greater birth weight of Holstein calves compared with those of beef breeds (Ferrell et al., 1976a; Bell et al., 1995).
Consistent with greater conceptus growth rates, initial protein accretion rates in the conceptus were 5.58\%/d in Holsteins versus 4.91\%/d in beef breeds, and the decay rates were $0.00791 \% / \mathrm{d}^{2}$ versus $0.00587 \% / \mathrm{d}^{2}$, respectively.

Despite greater initial rates of growth for Holstein conceptuses, the initial rate of uterine growth was $1.93 \% / \mathrm{d}$ for Holsteins versus $2.03 \% / \mathrm{d}$ for beef cattle, with decay rates of $0.00239 \% / \mathrm{d}^{2}$ versus $0.00268 \% / \mathrm{d}^{2}$, respectively.

Incorporation of the pregnancy model into Molly only slightly improved prediction errors with a $1 \%$ overall improvement in the LLF compared with the changes associated with the above hormonal work. Many cows on the study were dried off around d 200 of gestation at which point the gravid uterus is predicted to weigh $31 \mathrm{~kg}$. Although this is a significant amount of BW, it

Table 4. Parameter estimates derived from fitting equations [5] to [12] to the data of Bell et al. (1995)

\begin{tabular}{llccc}
\hline Parameter & Equation & Estimate & SD & SD (\% of estimate) \\
\hline$K_{\text {UterSyn }}$ & {$[5]$} & $1.93 \times 10^{-2}$ & $3.6 \times 10^{-5}$ & 0.2 \\
$K_{\text {UterSynDecay }}$ & {$[5]$} & $2.39 \times 10^{-5}$ & $1.4 \times 10^{-7}$ & 0.6 \\
$K_{\text {ConCSyn }}$ & {$[7]$} & $2.54 \times 10^{-2}$ & $8.4 \times 10^{-4}$ & 3.3 \\
$K_{\text {ConcSynDecay }}$ & {$[7]$} & $2.50 \times 10^{-5}$ & $3.3 \times 10^{-6}$ & 13.2 \\
$K_{\text {PoncSyn }}$ & {$[12]$} & $5.58 \times 10^{-2}$ & $7.7 \times 10^{-4}$ & 1.4 \\
$K_{\text {PConcSynDecay }}$ & {$[12]$} & $7.91 \times 10^{-5}$ & $3.0 \times 10^{-6}$ & 3.8 \\
\hline
\end{tabular}




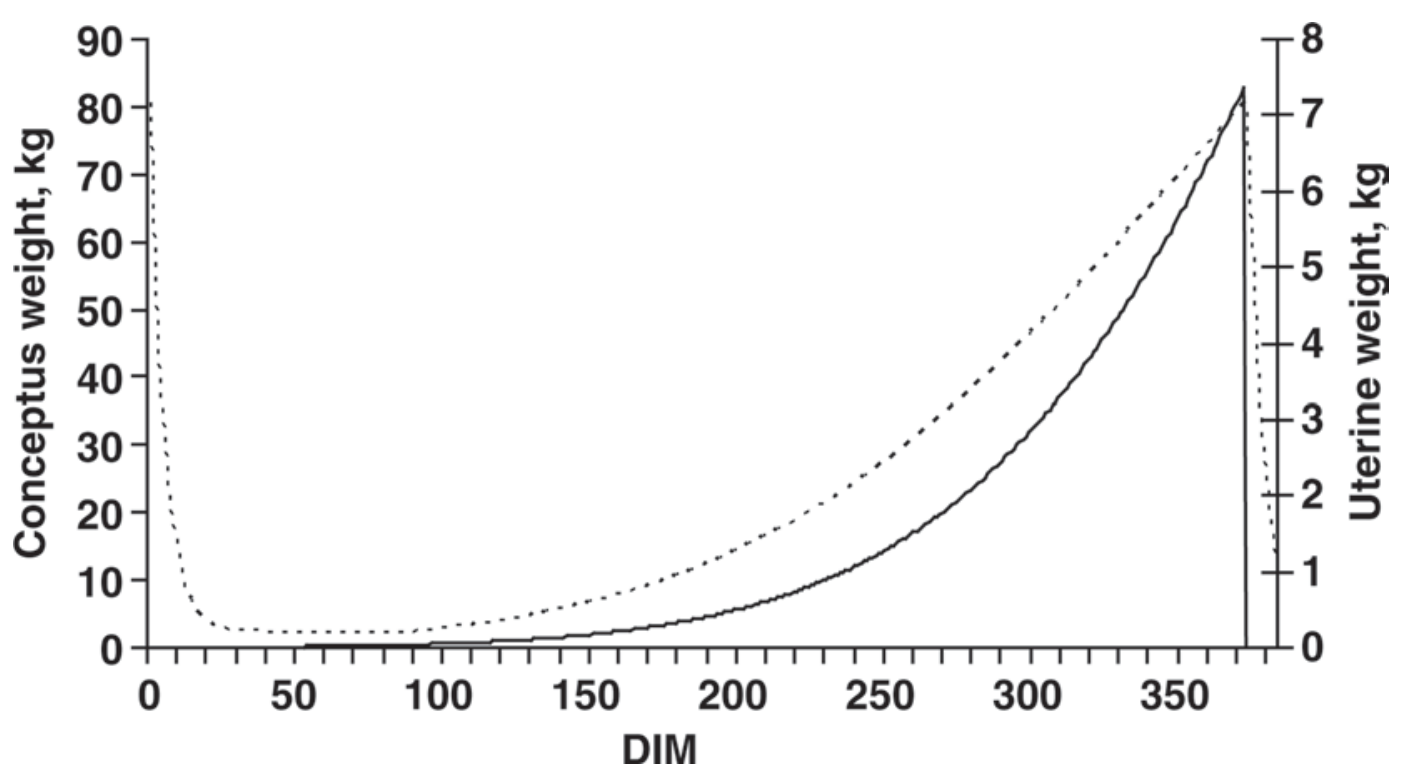

Figure 3. Predicted uterine (----) and conceptus (-) weights relative to days in milk with conception occurring at $90 \mathrm{~d}$ in milk. Predictions are from equations [5] and [7], respectively.

may not have been enough to detect given the variation in BW measures. Visual appraisal of residuals from d 100 of gestation until the end of the study for the model with and without the gestation submodel did not reveal any apparent differences in BW prediction errors, with many of the residuals lying on top of one another. Despite the apparent lack of benefit of considering gestational weight gain during the first $200 \mathrm{~d}$ of pregnancy with respect to BW prediction accuracy, the submodel would clearly allow more accurate predictions of $\mathrm{BW}$ through the transition period.

It could be argued that the gestation model would have provided more benefit if it had been introduced in the absence of the hormonal changes. However, the data do not support this point. If all of the benefits of the combination of changes in hormonal and gestational representations had been due solely to the gestational submodel, the parameter estimates for the hormonal components would have solved for values equivalent to the initial parameter estimates. Because the hormonal parameter estimates were almost identical when solving with and without the pregnancy submodel and neither set was similar to the original values, one must conclude that the improvements in prediction accuracy were primarily caused by the changes in hormonal representation and parameterization.

Although the combination of hormonal changes and representation of $\mathrm{BW}$ gain associated with pregnancy resulted in overall reductions in prediction errors and reductions in BW and BCS prediction errors, the changes clearly did not fully address problems during the early lactation period. Body weight and BCS loss are still underpredicted as are blood fatty acid concentrations and milk fat yields (Figure 1).

\section{Independent Model Challenge}

Fitting Molly2007 to the data of Aston et al. (1995) resulted in slightly different settings for mammary cells than previously observed (Hanigan et al., 2007) because of the inclusion of milk lactose percentage in the observed data [see Table 2 footnote vs. Hanigan et al. (2007)]. Prediction errors for simulations of the Aston et al. (1995) data were greater for Molly2008 than for Molly2007. The increased overall error was associated with slight increases in errors for milk yield, lactose yield, milk fat yield, BW, and BCS. However, the proportion of errors due to slope bias was decreased for milk and milk component yields and increased for BW and BCS. Mean bias was much greater for milk fat yield, but much less for BW and BCS.

The presence of large mean bias for predictions of milk fat suggests that derivation of the genetic scalars for milk composition using Molly2007 cannot be directly transferred for use in Molly2008. This is not surprising given the changes made in the representation of hormonal control of nutrient partitioning. The reductions in slope bias for milk and milk component yields suggest that Molly2008 is better able to simulate the differences in diets than Molly2007. This is important because a primary overriding objective of development of nutritional models is to provide accurate and precise predictions of responses to nutritional inputs.

The slope of residuals was $-0.57 \pm 0.09$ for $\mathrm{BW}$ and $-1.07 \pm 0.03$ for BCS, indicating that the model 
overpredicted changes in both of these entities. As the nutritional treatments in this study represented a greater range in the forage to concentrate ratio than employed by Kolver et al. (2007), these results may indicate that body mass changes may be over-responsive to high-grain diets. It could also reflect inherent genetic differences between British Friesians and North American and New Zealand Holsteins. As the Aston et al. (1995) work was conducted in early and mid lactation, the effects of pregnancy were not an issue. Additional evaluations of $\mathrm{BW}$ and $\mathrm{BCS}$ responses to nutrition are needed to determine if the observed slope bias represents a conceptual or parameterization problem in the model.

In conclusion, delinking the glucose set point for $H_{\text {Anab1 }}$ and $H_{C a t a b 1}$ and providing unique sensitivity exponents for each hormone resulted in significant improvements in model predictions of blood glucose and BCS. The majority of this reduction was caused by reductions in slope bias, although slope bias was actually worse for milk yield, milk protein yield, milk fat yield, and BW, suggesting that further refinement of the representation of those entities is required. The addition of a full description of metabolic demand and BW gain associated with pregnancy resulted in a very small additional improvement in overall prediction errors. An independent evaluation of the model did not show any improvement in predictions of BCS. Improvements in the representation of blood glucose should provide more reliable predictions of glucose supply and hormonal state, which is critical for further improvements in predictions of nutrient partitioning.

\section{ACKNOWLEDGMENTS}

This material is based upon work supported by the Cooperative State Research, Education and Extension Service, USDA, under project no. NC-1040. Funding for the work was also provided by DairyNZ Ltd. (Hamilton, New Zealand). The work of C. C. Palliser was funded by Dairy Insight (project no. 2031) on behalf of New Zealand dairy farmers. Any opinions, findings, conclusions, or recommendations expressed in this publication are those of the author(s) and do not necessarily reflect the view of the USDA.

\section{REFERENCES}

Aston, K., J. D. Sutton, and W. J. Fisher. 1995. Milk production from grass silage diets: Strategies for concentrate allocation. Anim. Sci. 61:465-480.

Baldwin, R. L. 1995. Modeling ruminant digestion and metabolism. Chapman and Hall, London, UK.

Baldwin, R. L., J. France, D. E. Beever, M. Gill, and J. H. Thornley. 1987a. Metabolism of the lactating cow. III. Properties of mechanistic models suitable for evaluation of energetic relationships and factors involved in the partition of nutrients. J. Dairy Res. 54:133-145.

Baldwin, R. L., J. France, and M. Gill. 1987b. Metabolism of the lactating cow. I. Animal elements of a mechanistic model. J. Dairy Res. 54:77-105.

Baldwin, R. L., J. H. Thornley, and D. E. Beever. 1987c. Metabolism of the lactating cow. II. Digestive elements of a mechanistic model. J. Dairy Res. 54:107-131.

Bell, A. W., R. Slepetis, and R. A. Ehrhardt. 1995. Growth and accretion of energy and protein in the gravid uterus during late pregnancy in Holstein cows. J. Dairy Sci. 78:1954-1961.

Beukes, P. C., B. S. Thorrold, M. E. Wastney, C. C. Palliser, and D. A. Clark. 2004. Modelling farm systems with once-a-day milking. Proc. N.Z. Soc. Anim. Prod. 64:237-240.

Beukes, P. C., B. S. Thorrold, M. E. Wastney, C. C. Palliser, K. A. Macdonald, K. P. Bright, J. A. S. Lancaster, C. A. J. Palmer, and M. J. Auldist. 2005. Modelling the bi-peak lactation curves of summer calvers in New Zealand dairy farm systems. Aust. J. Exp. Agric. 45:643-649.

di Marco, O. N., R. L. Baldwin, and C. C. Calvert. 1987. Relative contributions of hyperplasia and hypertrophy to growth in cattle. J. Anim. Sci. 65:150-157.

Ferrell, C. L., W. N. Garrett, and N. Hinman. 1976a. Growth, development and composition of the udder and gravid uterus of beef heifers during pregnancy. J. Anim. Sci. 42:1477-1489.

Ferrell, C. L., W. N. Garrett, N. Hinman, and G. Grichting. 1976b. Energy utilization by pregnant and non-pregnant heifers. J. Anim. Sci. $42: 937-950$.

Hanigan, M. D., H. G. Bateman, J. G. Fadel, J. P. McNamara, and N E. Smith. 2006. An ingredient-based input scheme for Molly. Pages 328-348 in Nutrient Digestion and Utilization in Farm Animals: A Modelling Approach. E. Kebreab, J. Dijkstra, A. Bannink, W. Gerrits, and J. France, ed. CAB International, Wallingford, UK.

Hanigan, M. D., J. France, D. Wray-Cahen, D. E. Beever, G. E. Lobley, L. Reutzel, and N. E. Smith. 1998. Alternative models for analyses of liver and mammary transorgan metabolite extraction data. $\mathrm{Br}$. J. Nutr. 79:63-78.

Hanigan, M. D., C. C. Palliser, and A. G. Rius. 2008. Modeling lactation potential in a whole animal model. Pages 485-506 in Mathematical Modelling in Animal Nutrition. J. France and E. Kebreab, ed. CAB International.

Hanigan, M. D., A. G. Rius, E. S. Kolver, and C. C. Palliser. 2007. A redefinition of the representation of mammary cells and enzyme activities in a lactating dairy cow model. J. Dairy Sci. 90:38163830 .

Harrison, J. H., D. D. Hancock, N. R. St-Pierre, H. R. Conrad, and W. R. Harvey. 1986. Effect of prepartum selenium treatment on uterine involution in the dairy cow. J. Dairy Sci. 69:1421-1425.

Holmes, C. W., I. M. Brookes, D. J. Garrick, D. D. S. Mackenzie, T. J Parkinson, and G. F. Wilson. 2002. Milk production from pasture. Principles and practices. Massey University, Palmerston North, New Zealand.

Kolver, E. S., J. R. Roche, C. R. Burke, J. K. Kay, and P. W. Aspin. 2007. Extending lactation in pasture-based dairy cows: I. Genotype and diet effect on milk and reproduction. J. Dairy Sci. 90:55185530.

Koong, L. J., W. N. Garrett, and P. V. Rattray. 1975. A description of the dynamics of fetal growth in sheep. J. Anim. Sci. 41:10651068 .

McNamara, J. P. 2004. Research, improvement and application of mechanistic, biochemical, dynamic models of metabolism in lactating dairy cattle. Anim. Feed Sci. Technol. 112:155-176.

McNamara, J. P., and R. L. Baldwin. 2000. Estimation of parameters describing lipid metabolism in lactation: Challenge of existing knowledge described in a model of metabolism. J. Dairy Sci. 83:128-143.

McNamara, J. P., J. H. Harrison, R. L. Kincaid, and S. S. Waltner. 1995. Lipid metabolism in adipose tissue of cows fed high fat diets during lactation. J. Dairy Sci. 78:2782-2796.

Palliser, C. C., K. P. Bright, K. A. Macdonald, J. W. Penno, and M. E. Wastney. 2001. Adapting the MOLLY cow model to fit production 
data from New Zealand animals. Proc. N.Z. Soc. Anim. Prod. 61:234-236.

Pullen, D. L., D. L. Palmquist, and R. S. Emery. 1989. Effect on days of lactation and methionine hydroxy analog on incorporation of plasma fatty acids into plasma triglycerides. J. Dairy Sci. 72:4958.

Roseler, D. K., D. Fox, A. Pell, and L. Chase. 1997. Evaluation of alternative equations for prediction of intake for Holstein dairy cows. J. Dairy Sci. 80:864-877.

Smith, N. E., W. L. Dunkley, and A. A. Franke. 1978. Effects of feeding protected tallow to dairy cows in early lactation. J. Dairy Sci. 61:747-756.

Vazquez-Anon, M., S. Bertics, M. Luck, R. R. Grummer, and J. Pinheiro. 1994. Peripartum liver triglyceride and plasma metabolites in dairy cows. J. Dairy Sci. 77:1521-1528.

Waltner, S. S., J. P. McNamara, and J. K. Hillers. 1994. Validation of indirect measures of body fat in lactating cows. J. Dairy Sci. $77: 2570-2579$

\section{APPENDIX}

The following is a description of additional equations required to integrate gravid uterine metabolism into Molly. Essentially, all of the following equations are stoichiometric conversions. Abbreviations used adhered to the following form: $\mathrm{d} A / \mathrm{d} t, F_{A, B}$, and $C_{A}$ represented the change in pool $A$ with respect to time $(\mathrm{mol} / \mathrm{d}$ or $\mathrm{kg} / \mathrm{d})$, the flux of substrate $A$ to product $B(\mathrm{~mol} / \mathrm{d}$ or $\mathrm{kg} / \mathrm{d})$, and the concentration of $A(\mathrm{~mol} / \mathrm{L})$, respectively; $f_{A, B}$ and $K_{A, B}$ represented a stoichiometric coefficient for conversion of $A$ to $B$ and a rate parameter for conversion of $A$ to $B$, respectively; $W t_{A}$ and $M W_{A}$ referred to the mass $(\mathrm{kg})$ present in pool $A$ and the molecular weight $(\mathrm{g} / \mathrm{mol})$ of molecule $A$, respectively.

The equations describing the change in uterine weight with respect to time $(\mathrm{kg} / \mathrm{d})$ were

$$
\begin{gathered}
\frac{\mathrm{d} W t_{\text {Uter }}}{\mathrm{d} t}=F_{\text {UterSyn }}-F_{\text {UterDeg, }} \\
F_{\text {UterSyn }}=W t_{U t e r} \times\left(K_{\text {UterSyn }}-2 \times K_{\text {UterSynDecay }} \times D O G\right) \\
\times \text { Preg }, \\
F_{\text {UterDeg }}=\left(W t_{U t e r}-i W t_{U t e r}\right) \times K_{U t e r D e g} \times \text { NonPreg. }
\end{gathered}
$$

Uterine protein $(\mathrm{kg})$ and changes in uterine protein over time $(\mathrm{kg} / \mathrm{d})$ were calculated from uterine mass as

$$
\begin{gathered}
W t_{\text {PUter }}=W t_{\text {Uter }} \times f_{\text {PUter }}, \\
\frac{\mathrm{d} W t_{\text {PUter }}}{\mathrm{d} t}=F_{\text {PUterSyn }}-F_{\text {PUterDeg }}, \\
F_{\text {PUterSyn }}=F_{\text {UterSyn }} \times f_{\text {PUter }},
\end{gathered}
$$

$$
F_{\text {PUterDeg }}=F_{\text {UterDeg }} \times f_{\text {PUter }}
$$

where $f_{\text {PUter }}$ represented the proportion of uterine mass represented by protein $(0.133 \mathrm{~g}$ of $\mathrm{CP} / \mathrm{g}$ of wet weight; Ferrell et al., 1976a).

The protein accretion rate for the gravid uterus was calculated from conceptus and uterine protein fluxes:

$$
\frac{\mathrm{d} W t_{P G r v U t e r}}{\mathrm{~d} t}=F_{\text {PConcSyn }}+F_{\text {PUterSyn }}-F_{\text {PUterDeg }}
$$

where the net protein synthesis rate of the conceptus $\left(F_{P C o n c S y n}, \mathrm{~kg} / \mathrm{d}\right)$ was

$$
\begin{aligned}
F_{\text {PConcSyn }} & =W t_{P \text { Conc }} \times\left(K_{\text {PConcSyn }}-2 \times K_{\text {PConcSynDecay }}\right. \\
& \times D O G) \times \text { Preg. }
\end{aligned}
$$

The mass of protein in the gravid uterus $(\mathrm{kg})$ was calculated as

$$
W t_{\text {PGruter }}=W t_{\text {PConc }}+W t_{\text {PUter }} .
$$

The differential equation describing changes in AA with respect to time $(\mathrm{mol} / \mathrm{d})$ was altered from the original representation (Baldwin, 1995) to reflect net deposition of AA in gravid uterine protein $\left(F_{A a, P G e s t}\right.$; $\mathrm{mol} / \mathrm{d}$ ) and catabolism of AA by the gravid uterus

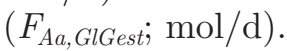

$$
\begin{aligned}
\frac{\mathrm{d} A a}{\mathrm{~d} t} & =F_{A b s, A a}+F_{P O t h, A a}+F_{P V i s, A a}-F_{A a, P O t h}-F_{A a, P V i s} \\
& -F_{A a, P m}-F_{A a, G l}-F_{S a P s, A a}-F_{A a, P G e s t}-F_{A a, G l G e s t},
\end{aligned}
$$

$$
\begin{gathered}
F_{A a, P G e s t}=F_{A a, P C o n c}+F_{A a, P U t e r}-F_{P U t e r, A a}, \\
F_{A a, G l G e s t}=W t_{\text {GrvUter }} \times K_{A a, \text { GlGest }} \times C_{A a},
\end{gathered}
$$

$$
F_{A a, P C o n c}=\frac{F_{P C o n c S y n} \times \text { Preg }}{M W_{\text {ProtAa }}},
$$

$$
F_{\text {Aa,PUter }}=F_{\text {PUterSyn }} / M W_{\text {ProtAa }},
$$

$$
F_{\text {PUter }, A a}=F_{\text {PUterDeg }} / M W_{\text {ProtAa }} .
$$


Parameter $K_{A a, G l G e s t}$ was set to a value of 6.0 to achieve an AA degradation rate approximately twice the net protein deposition rate in accordance with estimates of Bell et al. (1995); $M W_{\text {ProtAa }}$ represented the average molecular weight of AA in protein, assumed to be $110 \mathrm{~g} /$ mol of protein throughout the model (Baldwin, 1995).

The differential equation describing blood urea was altered to reflect generation of urea from AA degradation by the gravid uterus $\left(F_{A a, U r G e s t}\right)$ :

$$
\begin{aligned}
\frac{\mathrm{d} B l d U r}{\mathrm{~d} t} & =F_{A a, U r}+F_{A a, U r G e s t}+F_{A m, B l d U r}-F_{B l d U r, R u m A m} \\
& -F_{S a N, \text { RumAm }}-F_{B l d U r, M U N}-F_{B l d U r, U r i n e}
\end{aligned}
$$$$
F_{A a, U r V i s}=F_{A a, G l V i s} \times f_{A a G l U r},
$$$$
F_{A a, U r G e s t}=F_{A a, G l G e s t} \times f_{A a G l U r},
$$

where $f_{A a G l U r}$ represented the average stoichiometric value for $\mathrm{N}$ released from AA catabolism $(0.62 \mathrm{~mol}$ of urea/mol of AA) assumed in Molly.

Body nitrogen balance was altered to reflect nitrogen deposition in the gravid uterus in addition to the previous consideration of changes in blood AA, body protein, and visceral protein:

$$
\begin{aligned}
\text { Nbody } & =\left(\frac{\mathrm{d} A a}{\mathrm{~d} t}+\frac{\mathrm{d} P \text { Oth }}{\mathrm{d} t}+\frac{\mathrm{d} P \text { Vis }}{\mathrm{d} t}+F_{\text {Aa,PGest }}\right) \\
& \times F_{A a, F v A m} \times M W_{N} .
\end{aligned}
$$

The ATP use equations were altered to reflect ATP use $(\mathrm{mol} / \mathrm{d})$ in support of gestational growth and maintenance $\left(F_{A t, A d G e s t}\right)$ and for catabolism of AA by the gravid uterus and conversion to urea in the body $\left(F_{A a, U r G e s t}\right)$ :

$$
\begin{gathered}
F_{A t, A d}=F_{A t, A d O t h}+F_{A t, A d A d i p}+F_{A t, A d V i s}+F_{A t, A d G e s t}, \\
F_{A t, A d 15}=\left(F_{A a, U r V i s}+F_{A a, U r G e s t}+F_{A m, U r}\right) \times f_{A t A m U r},
\end{gathered}
$$

where ATP use by the gravid uterus was assumed to be a function of protein deposition and turnover:

$$
F_{A t, A d G e s t}=F_{A t, A d G e s t \text { Grth }}+F_{A t, A d G e s t T O}
$$

$$
\begin{aligned}
& F_{\text {At,AdGestTO }}=W t_{\text {PGrvUter }} / M_{\text {PVis }} \times f_{\text {GrvUterTO }} \times f_{\text {AaPxAd }}, \\
& F_{A t, A d G e s t \text { Grth }}=\left(F_{\text {Aa,PUter }}+F_{A a, P C o n c}\right) \times f_{A a P x A d} .
\end{aligned}
$$

Turnover was assumed to be $60 \%$ per day $\left(f_{\text {GrvUterTo }}\right)$, which resulted in total energy usage for gestation that was similar to that observed by Ferrell et al. (1976b). The ATP use associated with growth of the gravid uterus $\left(F_{\text {At,AdGestGrth }}, \mathrm{mol} / \mathrm{d}\right)$ was calculated from net AA deposition rates using the general model assumption of $5 \mathrm{~mol}$ of ATP/mol of peptide bond (Baldwin, 1995).

The maintenance heat production equation was altered to reflect energy loss associated with gestational ATP use:

$$
\begin{gathered}
\frac{\mathrm{d} \text { Maint }}{\mathrm{d} t}=H t M_{\text {Oth }}+H t M_{A d i p}+H t M_{V i s}+H t M_{\text {Gest }}, \\
H t M_{\text {Gest }}=F_{A t, A d G e s t} \times f_{A t A d H t} .
\end{gathered}
$$

The partial heats of maintenance for growth, protein turnover, and catabolism of AA $\left(H t_{A a G l}\right)$ were calculated as

$$
\begin{gathered}
H t M_{\text {GestGrth }}=F_{A t, A d G e s t G r t h} \times f_{\text {AtAdHt }}, \\
H t M_{\text {GestTO }}=F_{A t, A d G e s t T O} \times f_{A t A d H t}, \\
H t_{A a G l}=\left(F_{A a, G l V i s}+F_{A a, \text { GlGest }}\right) \times f_{A a G l H} .
\end{gathered}
$$

Energy deposition in the gravid uterus was calculated as

$$
\frac{\mathrm{d} G e s t E}{\mathrm{~d} t}=F_{\text {AaPGest }} / f_{\text {Gest } \operatorname{Pr} t} \times H C_{A a}
$$

and used in the calculation of energy balance $(E B$, $\mathrm{mcal} / \mathrm{d})$

$$
E B=\frac{\mathrm{d} O t h E}{\mathrm{~d} t}+\frac{\mathrm{d} A d i p E}{\mathrm{~d} t}+\frac{\mathrm{d} V i s E}{\mathrm{~d} t}+\frac{\mathrm{d} G e s t E}{\mathrm{~d} t} .
$$

